\title{
The roles of inter-fuel substitution and inter-market contagion in driving energy prices: Evidences from China's coal market
}

\author{
Jianglong $\mathrm{Li}^{\mathrm{a}, \mathrm{b}}$, Chunping Xie ${ }^{\mathrm{c} *}$, Houyin Long ${ }^{\mathrm{d}}$
}

\begin{abstract}
a. School of Economics and Finance, Xi'an Jiaotong University, Xi'an, Shaanxi 710049, PR China
b. Harvard John A. Paulson School of Engineering and Applied Sciences, Harvard University, Cambridge, Massachusetts 02138, United States

c. Grantham Research Institute, London School of Economics and Political Science (LSE), London WC2A 2AE, United Kingdom

d. School of Economics \& Management, Fuzhou University, Fuzhou 350108, China
\end{abstract}

\begin{abstract}
Coal has been dominating energy supply and consumption in China, with the country becoming the largest energy supplier and consumer worldwide. Due to inter-fuel substitution of crude oil and intermarket contagion of international coal market, China's coal price might be interrelated with crude oil price and international coal price. However, the precise roles of these two effects in determining China's coal price are unknown. This paper contributes to previous literature by investigating this issue. We find that co-movements between China's coal price and crude oil price largely hinge on the shares of oil and coal in China's energy mix, while its co-movements with international coal price depend on scales of coal trade. Inter-fuel substitution dominated the interaction of China's coal market with other energy types, but the importance of inter-market contagion has been increasing. We also find that China might have become an originator for driving the returns of crude oil and international coal, in particular after 2008. Furthermore, China's coal market is still a net volatility recipient for shocks from both crude oil market and international coal market. Given the increased integration of global energy markets, we anticipate this paper to provide a better understanding on the dynamic changes in China's coal prices.
\end{abstract}

Keywords: China's coal price; inter-fuel substitution; inter-market contagion; crude oil market; international coal market

\section{Introduction}

\footnotetext{
${ }^{*}$ Corresponding author at: Grantham Research Institute, London School of Economics and Political Science (LSE), London WC2A 2AE, United Kingdom.

E-mail address of corresponding author: c.xie6@lse.ac.uk (C. Xie).

E-mail address of co-authors: lijianglong@seas.harvard.edu (J. Li), longhouyin1985@163.com (H. Long)
} 


\subsection{China's coal market}

Since 2011, China has become the largest global primary energy consumer, and coal accounted for $60 \%$ of China's total primary energy consumption in 2017 (see Figure 1). Meanwhile, China has surpassed the United States (US) as the largest electricity user, and more than $70 \%$ of its electricity is generated by coal-fired power plants. At present, China has taken up about $50 \%$ of world's coal consumption. At least for the near future, coal is likely to maintain dominance based on China's resource endowment. According to BP (2018), coal accounts for 92.1\% of China's fossil fuel reserves, while oil and natural gas account for only 3.3\% and 4.6\%, respectively ${ }^{1}$. On the other hand, increase from non-fossil fuels will still be limited due to their high cost and technical difficulties in power grid interconnection (Lin and Li, 2015a).

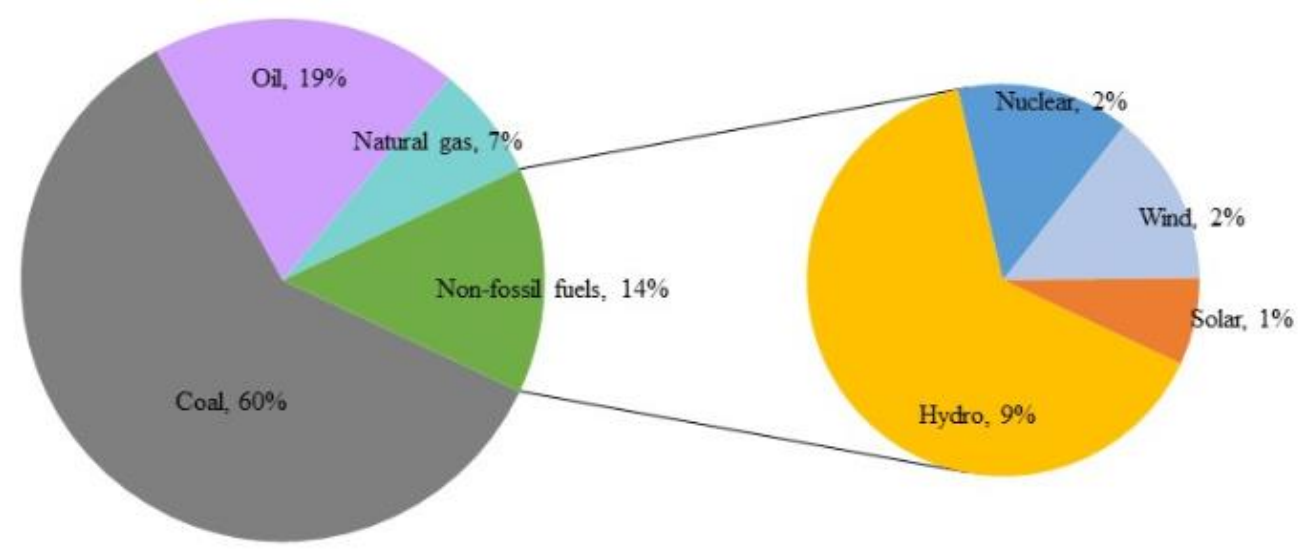

Figure 1. China's energy mix in 2017

As the world's largest producer and consumer of coal, China is facing significant economic uncertainty resulted from coal price fluctuations (Guo et al., 2016). According to Kilian (2009), coal price is determined endogenously by: i) coal market fundamentals such as coal supply and demand; ii) coal market-specific factors such as speculation and spillover. From the perspective of spillover, there are two crucial channels that drive China's coal price changes.

The first is the co-movement with crude oil prices due to inter-fuel substitution in energy consumption. An increase (decrease) in crude oil prices would motivate energy consumers to substitute coal towards (from) petroleum products, which increases (decreases) demand for coal and hence coal prices. Oil and coal are competitive substitutes mainly through the substitutions between petroleum products and electricity, of which over $70 \%$ is generated by coal-fired power plants. Furthermore, inter-substitution in this paper is a generalized concept in time dimension. Energy resource is both a commodity and a kind of asset which is storable. Therefore, energy demand is the sum of demand for current use and inventory for future consuming (Kilian and Murphy, 2014).

1 The proved reserves of coal, crude oil, and natural gas are 138818.9 million tonnes, 3500 million tonnes, and 5.5 trillion cubic meters, respectively. 
Taking the change of inventory into consideration, the generalized inter-fuel substitution may take place instantaneously. For example, when the increase of oil prices shifts the expectations of forwardlooking market participants, they might assume that energy consumers are likely to substitute oil using coal and thus increase coal consumption and coal prices. This will induce a reaction from market participants to accumulate coal inventories given that they expect coal price increasing along with oil price rise. As a result, the desirability of holding coal inventories changes in response to news about oil price fluctuations. By altering the current behaviors of commercial traders on coal markets, price and volatility spillover between coal markets and oil markets through inter-fuel substitution can occur even within a short period. In addition, crude oil accounts for about $18 \%$ of China's primary energy consumption, and comparing to natural gas, the relative size of oil consumption is large enough to affect the consumption of coal by inter-fuel substitution.

The second driver is the co-movement with the international coal market arise from inter-market contagion. This could be caused by the coal arbitrage. The law of one price suggests that coal prices in different markets would converge because coal could flow across markets through trading and arbitrage of traders would eliminate the price differentials across markets (Parsley and Wei, 2001). Before mid-2008, China was a net exporter of coal. If China's domestic coal price was lower, coal suppliers would tend to export more which would increase the price of domestic coal and decrease the international coal price, and vice versa. Ever since mid-2008, China has become a net importer of coal. Coal consuming firms in the southeastern coastal area could either buy coal from domestic coal producers, or import coal from foreign suppliers through international trade. Also, the scale of international trade of coal appears to be large enough to affect domestic coal prices, which accounts for about $9 \%$ of China's total consumption in recent years.

\subsection{Motivation}

Generally speaking, understanding changes in coal price is important for several reasons. First, coal is an important input factor in production. As a result, a decrease in coal price could reduce the cost for industrial consumers, and thus energy price changes could be regarded as supply shocks to the economy (Barro, 2007). For example, due to the continuous low coal price, the electricity price for industry decreased by 3 cents/kWh after January 2016, which meant a 120 billion RMB cost saving for industrial firms. Second, coal price changes would generate a substantial cost-push impact through the linkages across sectors, as coal is in the upstream section of industries and is mainly used as an intermediate input (Lin et al., 2014). Third, coal price change is a kind of uncertainties and risks, thus changes in coal price might have dramatically negative effects on investment decision of firms (Atkeson and Kehoe, 1999), which may impede capital accumulation and then output.

Understanding drivers behind coal prices is particularly important for China due to its coaldominated energy mix. China's coal prices can be affected by inter-fuel substitution through crude oil market and inter-market contagion through international coal market, and these interactions can 
be quantified in terms of returns (first moment) and volatility (second moment). For returns, the sharp increases or decreases in world oil and coal prices may generate substantial shocks affecting China's domestic coal price and hence influence the cost and investment incentives for industrial coal consumers, which may harm economic growth. Therefore, it is necessary to identify the originators of return shocks. As for volatility, it is an important factor for market participants because it is often interpreted as a proxy for information flow (Ewing et al., 2002; Lin and Li, 2015). It is necessary to explore how volatility and information flow between different markets, as participants (real or financial) can use these detailed information connections to find optimal hedging positions and thus reduce uncertainty (Lin and Wesseh, 2014; Lin and Li, 2015b).

Unexpected shocks in energy commodity prices bring about high uncertainties to economy due to its high dependency on energy resources (Chen, 2014). Coal stands out among energy commodities because of its importance for China, the world's largest energy consumer. As a result, in order to identify coal price movements and generate more accurate expectations in China's coal market, this paper focuses on empirical study of China's coal price in return and volatility, investigating coal price fluctuations caused by inter-fuel substitution from crude oil market and inter-market contagion from international coal market.

The remainder of this paper is organized as follows. In Section 2, we briefly review the existing literature which investigate the interaction among different energy prices, both inter-fuels and intermarkets. Section 3 describes the dataset used in this paper and provides a preliminary analysis of the time series. Section 4 discusses the model specification in detail, including the corrected Dynamic Conditional Correlation (cDCC) model and spillover index. Section 5 presents the empirical results and further discussions. The final section provides some concluding remarks.

\section{Literature Review}

The existence of an integrated commodity market is implied by the economic theory of the law of one price. The interaction across markets can be captured by spillovers (in terms of either returns or volatility). A large number of literature has already investigated the integration of energy markets extensively, especially for crude oil market ever since the 1970s oil price shocks. Most studies examine the spillover across stock markets or between the crude oil market and financial market. For example, Malik and Hammoudeh (2007) examined the volatility and shock transmission mechanism among global crude oil market, US and Gulf equity markets. Sadorsky (2012) analyzed the correlations and volatility spillovers between oil prices and the stock prices of clean energy companies and technology companies.

In terms of methods, Arouri et al. (2012) argued that GARCH-type approach had received a particular interest from almost all previous literatures for capturing the spillover effect. For example, 
(Malik and Ewing (2009) employed bivariate GARCH models to investigate volatility transmission between oil prices and equity sector returns; Ewing and Malik (2013) applied univariate and bivariate GARCH models to study volatility transmission between gold and crude oil markets; Lin and Li (2015) examined price and volatility spillover across natural gas and crude oil markets using MGARCH model; Ahmad (2017) investigated the directional spillover between crude oil prices and stock prices of technology and clean energy companies. It is worth noting that although these models were built for financial market in the first place, they can also be applied to energy market because either coal, oil or natural gas is traded as an asset by speculators, as well as being pure a commodity (Kilian and Murphy, 2014).

The gradually increasing integration among different markets has motivated several efforts to evaluate the degree of market integration through spillover, both within and between coal, crude oil and natural gas markets. For example, Erdős (2012) examined the relationship between crude oil and natural gas in the US and UK, and found that gas prices in the UK have remained integrated with crude oil prices, but US gas prices decoupled after 2009 due to the oversupply of shale gas in the US and the limitation on gas export capacity. Bachmeier and Griffin (2006) tested the price spillovers for coal, crude oil and natural gas and found that coal, crude oil and natural gas markets are only weakly integrated.

Apart from market integration, another issue being more intensively investigated in recent years is the volatility interactions within and across different energy markets. This may have been prompted by the contemporaneous large fluctuations in energy prices, for example, the turmoil around 2008 as well as the continuous fall in price since 2014. For example, Gardebroek and Hernandez (2013) examined volatility transmission of crude oil and ethanol prices. They also argued biofuels such as bioethanol and biodiesel are technological replacements for petroleum products, thus the crude oil market may generate effects on agriculture commodity prices as well. Relevant studies include Asche et al. (2012), Wu and Li (2013), Antonakakis et al. (2018) and Batten et al. (2019).

With regards to the studies mentioned, there are two issues that remained to be addressed. First, most of the existing studies examined the spillovers of price and volatility separately, yet it is necessary to provide an approach which studies price and volatility spillovers in a comprehensive framework. Lin and $\mathrm{Li}$ (2015b) and Serletis and Xu (2016) investigated both the price and volatility spillover effects in a single framework, but one limitation of these two studies is that they cannot assess the dynamics changes of spillover magnitude. And very recently, Batten et al. (2019) examined the degree of integration of the global steam coal market and concluded that China provides a major source of volatility to the global coal market. Second, limited attention has been paid to coal prices. Given the large coal consumption and the increased integration of energy markets, coal price analysis appears to be increasingly important. Bachmeier and Griffin (2006), Serletis and Xu (2016) and Batten et al. (2019), as mentioned above, are the few exceptions that examined coal prices. 
The scarcity of studies on coal prices in the field of price and volatility spillovers, as well as the importance of coal to China, have provided a compelling motivation for this paper. This paper contributes to the existing literature in the following ways: First of all, it fills the research gap concerning China's coal prices, as only very few studies have focused on this issue. Although numerous studies have been conducted on crude oil prices, coal also particularly matters for China's energy issues because it accounts for over 60\% in China's energy mix. Relevant studies on China's coal market are still nascent. Second, inter-fuel substitution and inter-market contagion are two important mechanisms that could affect China's coal prices, or vice versa. To the best of our knowledge, no study has investigated the interaction between China's domestic coal market, the international coal market and crude oil market. Third, the spillover index has been further applied to examine the dynamics of return and volatility spillovers. In particular, we find evidence of different mechanisms in inter-fuel substitution and inter-market contagion which affect China's coal prices, as well as divergent behavior in return and volatility spillovers.

\section{Data and preliminary analysis of time series}

Due to the geographical segmentation of the coal markets, coal prices in both China's domestic and international markets are employed for analyzing the inter-market contagion. Meanwhile, crude oil price is also included in order to investigate the price co-movement from inter-fuel substitution.

First of all, coal price in Qin Huang Dao (QHD) is used as the indicator of China's coal price. QHD is the largest coal shipment port in China whose coal throughout accounts for more than 30\% of China's total. The QHD coal price is usually regarded as the most authoritative indicator reflecting coal prices in China. Second, we employ the Australia BJ steam coal price ${ }^{2}$ (Aus_BJ) as the indicator for the international coal price. As for the international coal market, steam coal and coking coal are the two main products for international trade, with steam coal taking up more than $70 \%$ of the international coal trade. Australia is a major global coal supplier whose steam coal exports were 200 million tons in 2017 (Minerals council of Australia, 2018) ${ }^{3}$. On the other hand, China is the largest importer of coal with Australian coal being the main source of steam coal'4. Thus, we use Aus_BJ to explore the inter-market contagion of international coal trading on the dynamics of China's coal price. We also show later in section 5 why not to use coal price in other regions that do not have much coal trade with China. Third, as for the crude oil market, Brent crude oil price serves as a major benchmark price for purchases of oil worldwide, which is also regarded as a major benchmark price in China's pricing mechanism of refined oil product. Thus, international oil price would be a better indicator than China's domestic crude oil price if one wants to investigate the spillovers between coal and oil

\footnotetext{
2 It is published by Barlow Jonker (BJ) Company. It is the spot price of coal shipping from Newcastle in Australia.

${ }^{3} \mathrm{http} / /$ minerals.org.au/sites/default/files/Coal\%20exports\%20set\%20all-time\%20record\%20in\%202017.pdf.

${ }^{4}$ Data for China's coal import can be seen in: http://mp.cnfol.com/8856/article/15514144447-138338482.html.
} 
markets from the perspective of inter-fuel substitution ${ }^{5}$. Relevant studies on global crude oil prices also mostly employ the Brent crude oil price as the main indicator (such as Arouri et al., 2012; Lin and Li, 2015).

As for data frequency, there are different data frequencies used in previous literature, including daily, weekly, monthly data (Lin and Li, 2015). Weekly spot prices are used in this paper due to: i) future prices are partly driven by other factors such as herd behavior and scalping, rather than market conditions (Gardebroek and Hernandez, 2013). In order to identify the impact of inter-fuel substitution and inter-market contagion, it is preferable to use spot prices. ii) As noted by Arouri et al. (2012) and Lin and Wesseh (2014), weekly data seems to capture the dynamic market interactions better than daily and monthly data. The reason is that the use of daily data often induces potential biases arising from the bid-ask bounce, non-synchronous trading days, and the effects of illiquidity on asset prices; whilst monthly data may mask some volatility transmission mechanisms due to time aggregation.

All weekly spot prices of coal are obtained from the Wind Database, and Brent oil spot price is available in the U.S. Energy Information Administration. Based on data availability, the sample period is from February 28, 2003 to Jun 5, 20196. The sample period is reasonable because China's coal price was not determined by the market until $2002^{7}$. The returns of price are calculated by:

$$
r_{i, t}=100 \times \ln \left(p_{i, t} / p_{i, t-1}\right)
$$

where $p$ denotes price; $r$ denotes the return measuring percent change of price; the subscript $i$ represents China's domestic coal, Australian coal or global crude oil; $t$ denotes time.

Figure 2 depicts the prices and returns for crude oil, QHD and Aus_BJ. It demonstrates that the price movements in the three markets seems to be highly correlated, with significant price spikes

\footnotetext{
${ }^{5}$ An alternative proxy for crude oil market is domestic oil price. The widely used domestic oil price in China is crude oil price of Daqing, which is the largest oil producer in China. But the production of Daqing oil field only provides about $6 \%$ of China's total oil consumption in recent years. Therefore, even oil price in Daqing still cannot represent the price level of China's oil market. Further, about 70\% of China's oil consumption in 2018 depends on imports, indicating that international oil price would heavily affect the price level of China's oil consumption.

6 This is the time we went through the last round of calculation.

7 Of China's coal consumption, about $55 \%$ is used to power generation, which is called steam coal. The price of the other $45 \%$ coal was basically determined by market (Lin and Jiang, 2011). However, in order to solve the imbalanced development between electricity market and coal market, Chinese government still provided a "guiding price" for thermal coal before 2002. This indicates that the price of coal in China was still directly influenced by government interventions. With China's ongoing market-oriented transition, Chinese government abolished the guiding price for thermal coal since 2002. The price of thermal coal began to be determined by power plants and coal firms. Therefore, we asserted that "China's coal price was not determined by the market until 2002". Also, It can be directly referred from Lin (2014, pp165).
} 
during 2007-2008, a price crash after the 2008 financial crisis and another after mid-2014. It also shows that crude oil price usually moves as an "originator" and then the movement spreads into the coal prices of QHD and AUS_BJ. Namely, coal prices seem to move as "recipients". In particular, the oil price crashes after the 2008 financial crisis and in the latter half of 2014 are both followed by a dramatic decrease in coal prices. In addition, as shown in Figure 2(b), all returns fluctuate around the mean value, which suggests they are stationary mean-reverting series, while the volatilities of returns are clustered, implying that the returns are series with an autoregressive conditional heteroscedastic $(\mathrm{ARCH})$ process (Lin and Li, 2015b). We take this into consideration in the model specification.

(a) The historical trends of prices

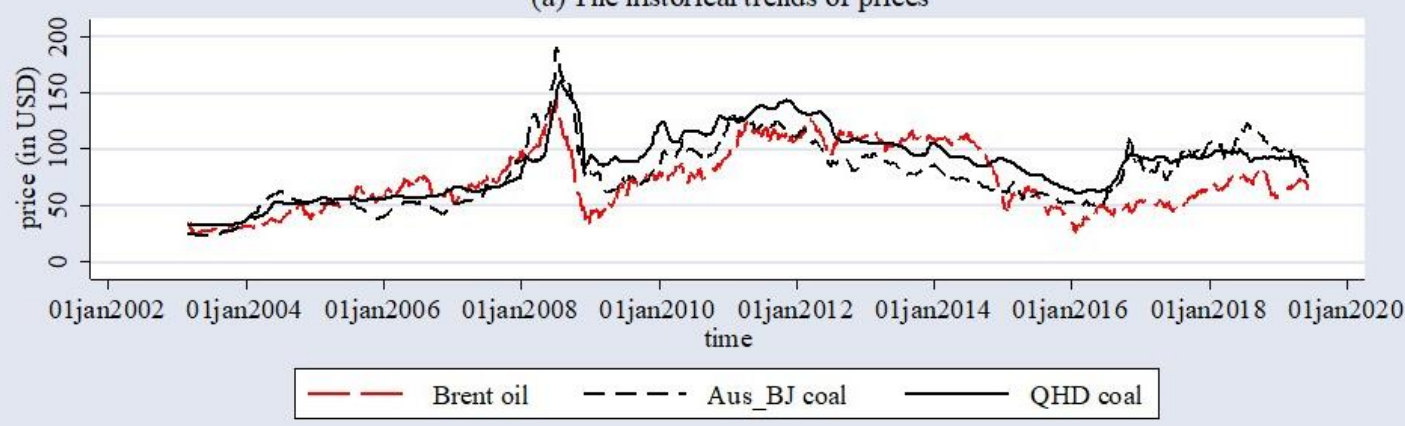

(b) The historical trends of returns

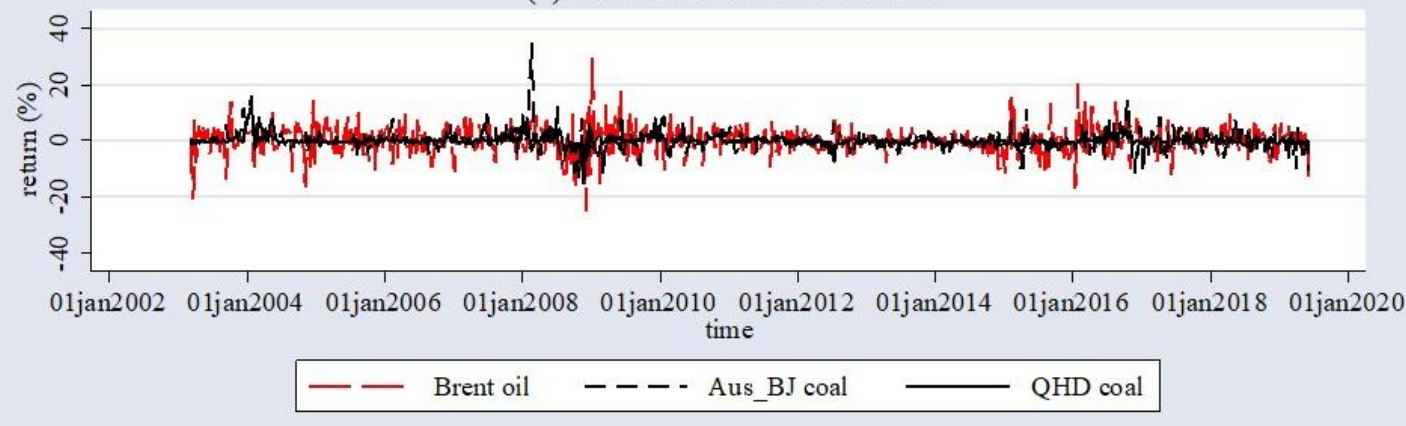

Figure 2. Price and return for each energy market

Notes: the unit for coal price is "USD/ton", for crude oil is "USD/barrel", for return rate is "\%". USD is abbreviation for United States Dollar.

Table 1 reports the descriptive statistics of prices and returns, correlation analysis is also conducted. Note that: i) the high correlation across different prices indicates that the co-movement is significant; ii) LB(6) and LBS(6) are Ljung-Box test for returns and squared returns, respectively, with six lags, which are both $\chi^{2}(6)$ distributed. The null hypothesis of Ljung-Box test is that there is no autocorrelation in the series. The number of lags is referred to Edwards and Susmel (2001) who also use weekly data. The LB statistics suggest that there is significant autocorrelation in returns, with the exception of Aus_BJ, indicating that we need to consider serial correlation in the multivariate analysis. 
The LBS statistics are also significant except for Aus_BJ, implying an ARCH type process for the conditional variance. Thus, a VAR-MGARCH specification is proposed for modeling the autocorrelation in returns and an $\mathrm{ARCH}$ process for conditional variance.

Table 1. Descriptive statistics for prices and returns and their correlation

\begin{tabular}{|c|c|c|c|c|c|c|}
\hline & \multicolumn{3}{|c|}{ Price } & \multicolumn{3}{|c|}{ Return } \\
\hline & QHD & Brent & Aus_BJ & QHD & Brent & Aus_BJ \\
\hline \multicolumn{7}{|c|}{ Descriptive statistics } \\
\hline Observation & 779 & 779 & 779 & 778 & 778 & 778 \\
\hline Mean & 87.09 & 73.13 & 78.86 & 0.126 & 0.078 & 0.136 \\
\hline Maximum & 160.7 & 143.9 & 190.9 & 12.92 & 30.68 & 34.94 \\
\hline Minimum & 32.74 & 24.39 & 23.75 & -13.59 & -25.34 & -15.64 \\
\hline Std.Deviation & 28.02 & 27.76 & 28.97 & 1.659 & 5.081 & 3.45 \\
\hline Skewness & 0.125 & 0.336 & 0.542 & 0.189 & -0.031 & 1.318 \\
\hline Kurtosis & 2.43 & 2.026 & 3.31 & 18.59 & 6.352 & 18.81 \\
\hline $\mathrm{LB}(6)$ & & & & $396.95^{* * *}$ & $168.43^{* * *}$ & 3.22 \\
\hline $\operatorname{LBS}(6)$ & & & & $152.00^{* * *}$ & $62.53^{* * *}$ & 6.64 \\
\hline \multicolumn{7}{|c|}{ Correlation } \\
\hline QHD & 1 & 0.751 & 0.881 & 1 & 0.096 & 0.190 \\
\hline Brent & & 1 & 0.696 & & 1 & 0.143 \\
\hline Aus_BJ & & & 1 & & & 1 \\
\hline
\end{tabular}

Notes: ${ }^{* * *}$ denotes significant at the $1 \%$ level.

In addition, time series data are not usually stationary, thus we check the stationarity of our sample by conducting a unit root test. As in the existing literature, two methods for testing the existence of unit roots are widely applied: the Augmented Dickey-Fuller test (ADF) and Dickey-Fuller GLS test (DF-GLS). In addition, there have been periods in which energy prices have exhibited structural breaks. Thus, a unit root test allowing for endogenous structural breaks, proposed by Zivot-Andrews (2002), is also applied. In order to reduce the heteroscedasticity in the time series, all prices were transformed by taking the natural logarithm. The results for energy prices in log level and in log difference (i.e., returns) scales are given in Table 2.

Table 2. Unit root tests

\begin{tabular}{ccccccc}
\hline \hline & \multicolumn{2}{c}{$\begin{array}{c}\text { Augmented Dickey and } \\
\text { Fuller }\end{array}$} & \multicolumn{2}{c}{ Detrended DF-GLS } & \multicolumn{2}{c}{ Zivot-Andrews } \\
\cline { 2 - 7 } & level & First-difference & level & First-difference & level & First-difference \\
\hline QHD & $-3.159^{* *}$ & $-16.562^{* * *}$ & -0.186 & $-5.196^{* * *}$ & -3.830 & $-10.528^{* * *}$ \\
Brent & -2.175 & $-27.500^{* * *}$ & -0.998 & $-4.317^{* * *}$ & -3.606 & $-27.824^{* * *}$ \\
Aus_BJ & $-2.780^{*}$ & $-21.904^{* * *}$ & -0.638 & $-6.399^{* * *}$ & -3.208 & $-16.173^{* * *}$ \\
\hline \hline
\end{tabular}

Notes: ${ }^{* * *},{ }^{* *}$ and ${ }^{*}$ denote the estimation is significant at $1 \%, 5 \%$ and $10 \%$, respectively. The lag length for the ADF is set using the Schwarz information criteria (SIC) and optimal lags for DF-GLS are determined by the Ng-Perron sequential decision rule. Both slope and intercept breaks are allowed in Zivot-Andrews test. For 
the three tests above, the null hypothesis is that the variable is non-stationary, and the alternative hypothesis is that the variable is generated by a stationary process.

The results of ADF, DF-GLS, and ZA tests in Table 2 suggest that crude oil, Aus_BJ and QHD prices might be non-stationary. Meanwhile, the results of the three unit root tests, when applied to the log difference of all prices, indicate that the three returns are stationary processes as they reject the hypothesis of the existence of unit roots.

Accordingly, the preliminary analysis suggests that, all the returns series are stationary with serial correlation and volatility clustering, and thus the VAR-MARCH (applied in Section 4) and dynamic spillover model (applied in Section 5) are appropriate methods for exploring their joint properties.

\section{Model specification}

Given the results in preliminary analysis, the first step is to identify the specification of mean equation using the VAR method. Based on Apostolakis and Papadopoulos (2014), the following mean equation is specified and estimated for returns series:

$$
R_{t}=\sum_{t=i}^{n} \varphi_{i} \cdot R_{t-i}+\varepsilon_{t}
$$

where $R_{t}=\left(r_{t}^{O i l}, r_{t}^{A u S_{-} B J}, r_{t}^{Q H D}\right)^{\prime}$ denotes the vector of returns, $\varphi$ is a $3 \times n$ matrix of estimated coefficients capturing autocorrelation, and $n$ represents the length of the lag in the mean equation.

Furthermore, there are clustering volatilities in the residuals of VAR. Hence, the multivariate $\mathrm{GARCH}(\mathrm{MGARCH})$ model is applied to specify the variance equation, which is given by:

$$
\varepsilon_{t}=\left(\begin{array}{l}
\varepsilon_{t}^{O i l} \\
\varepsilon_{t}^{A u s_{-} B J} \\
\varepsilon_{t}^{Q H D}
\end{array}\right)=H_{t}^{1 / 2}\left(\begin{array}{l}
v_{t}^{O i l} \\
v_{t}^{A u s_{-} B J} \\
v_{t}^{Q H D}
\end{array}\right)
$$

where $v_{t}=\left(v_{t}^{\text {Oil }}, v_{t}^{\text {Aus }{ }_{-}^{B J}}, v_{t}^{\text {OHD }}\right)^{\prime} \sim \operatorname{iidN}\left(0, I_{3 \times 3}\right)$, and $H_{t}$ is a positive definite matrix for all $t$, which captures the conditional variance of $\varepsilon_{t}$ :

$$
\operatorname{Var}\left(\varepsilon_{t} \mid \Omega_{t-1}\right)=\operatorname{Var}_{t-1}\left(\varepsilon_{t}\right)=H_{t}^{1 / 2} \operatorname{Var}_{t-1}\left(v_{t}\right)\left(H_{t}^{1 / 2}\right)^{\prime}=H_{t}
$$

where $\Omega_{t-1}$ is the information set in period $t-1$.

The second step is to formulate the conditional variance matrix $H_{t}$. The specification needs to 
be flexible as well as parsimonious for the estimating purpose and empirical explanation. However, the flexibility usually contradicts with the parsimony. Thus, an important intention in $\mathrm{MGARCH}$ models is how to balance between parsimony and flexibility (Silvennoinen and Terasvirta, 2009). In addition, positive definiteness of the conditional variance matrix needs to be guaranteed, which is usually achieved by eigenvector decomposition.

Correlation models are feasible specification for balancing flexibility and parsimony, while ensuring positive definiteness of the conditional variance matrix as well. The simplest multivariate correlation model is Constant Conditional Correlation (CCC-) GARCH model. However, the assumption of the constant conditional correlations may be too restrictive because the correlations could be time-dependent. Thus, the time-invariance assumption has been relaxed to be time-varying, which can be decomposed as the following form:

$$
H_{t}=D_{t} P_{t} D_{t}
$$

where $D_{t}=\operatorname{diag}\left(h_{11, t}^{1 / 2}, h_{22, t}^{1 / 2}, h_{33, t}^{1 / 2}\right)$ is the diagonal matrix of square root conditional variances, and $h_{i i, t}$ is the conditional variance determined by the univariate GARCH model. The subscript: 1 stands for Brent oil, 2 stands for Aus_BJ, 3 stands for QHD; respectively. Hereafter, the notations are in the similar way.

In order to specify the time-varying $P_{t}$, Engle (2002) introduced a dynamic matrix process as:

$$
Q_{t}=(1-\alpha-\beta) S+\alpha v_{t-1} v_{t-1}^{\prime}+\beta Q_{t-1}
$$

where $\alpha$ and $\beta$ are non-negative scalars, $v_{t}=\left(v_{1 t}, v_{2 t}, v_{3 t}\right)^{\prime}$ is the $3 \times 1$ vector of standardized residuals, $S$ is the unconditional correlation matrix of $v_{t}$, and $Q_{0}$ is positive definite. The positive defined correlation matrix $P_{t}$ can be obtained by rescaling $Q_{t}$ as follows:

$$
\begin{aligned}
P_{t} & =\left(I \square Q_{t}\right)^{-1 / 2} Q_{t}\left(I \square Q_{t}\right)^{-1 / 2} \\
& =\operatorname{diag}\left(q_{11}^{-1 / 2}, q_{22}^{-1 / 2}, q_{33}^{-1 / 2}\right) Q_{t} \operatorname{diag}\left(q_{11}^{-1 / 2}, q_{22}^{-1 / 2}, q_{33}^{-1 / 2}\right)
\end{aligned}
$$

where $\square$ denotes the Hadamard product of two matrices, $I$ is a $3 \times 3$ unit matrix, $q_{i j}$ is the $(i, j)$ element of $Q_{t}$.

The dynamic coefficient of $i$ and $j$ in time $t$ can be obtained by:

$$
\rho_{i j, t}=\rho_{j i, t}=q_{i j, t} / \sqrt{q_{i i, t} q_{i j, t}}
$$

The dynamic coefficient is used to show how the price volatility in one energy market relates to price volatility in another energy market. The magnitude ranges between -1 and 1 . A higher positive 
value implies a stronger direct relationship, while a lower negative value indicates a stronger inverse relationship. However, as proven by Aielli (2013), the above DCC estimation for correlation matrix, $S$, is not consistent in general, leading to the inconsistent estimators for the dynamic correlation parameters. Accordingly, Aielli (2013) proposes an improved method to estimate dynamic conditional correlation, i.e., the corrected DCC model (cDCC). In this paper, we apply the cDCC model to estimate the MGARCH process.

The VAR-MGARCH model can explore the co-movements of prices of Brent oil, Aus_BJ and QHD coal with respect to time; but it cannot analyze the direction and magnitude of the spillover of returns and volatilities, especially the dynamic trends of the spillover magnitude for given directions. While, it is the central issue for investigating the dynamic changes in China's coal prices from the perspectives of inter-fuel substitution and inter-market contagion. Thus, we further apply the DY method proposed by Diebold and Yilmaz (2009) to estimate the spillover magnitude for given directions.

Given that Brent oil, Aus_BJ and QHD prices would co-move which is detected by MGARCH process, we take the 3-variable and $p$ th order VAR:

$$
x_{t}=\sum_{i=1}^{p} \Phi_{i} x_{t-i}+\varepsilon_{t}
$$

where $x_{t}=\left(x_{1 t}, x_{2 t}, x_{3 t}\right)^{\prime}$ represents the vector of either returns or volatilities, $\Phi$ is the parameter matrix, and $\varepsilon_{t}$ denotes the residual vector. The moving average form can be given as:

$$
x_{t}=\sum_{i=1}^{\infty} A_{i} \varepsilon_{t-i}
$$

where the $3 \times 3$ coefficient matrix $A_{i}$ can be calculated by the recursive process:

$$
A_{i}=\Phi_{1} A_{i-1}+\Phi_{2} A_{i-2}+\ldots+\Phi_{p} A_{i-p}
$$

Suppose that the variance matrix for the error is $\Theta$, the H-step-ahead forecast error variance decomposition is estimated by:

$$
\theta_{i j}(H)=\frac{\sigma_{j j}^{-1} \sum_{h=0}^{H-1}\left(e_{i}{ }^{\prime} A_{h} \Theta e_{j}\right)^{2}}{\sum_{h=0}^{H-1}\left(e_{i}{ }^{\prime} A_{h} \Theta A_{h}{ }^{\prime} e_{i}\right)}
$$

where $\sigma_{j j}$ denotes the standard deviation of the error term for the $j$ th equation; $e_{i}$ represents the selection vector whose $i$ th element is one, and zero otherwise.

The directional spillover between market $i$ and $j$ is simply the return or volatility shocks 
transmitted from market $i$ to market $j$. The original work of Diebold and Yilmaz (2009) proposes a spillover index by measuring the contribution of the spillovers of shocks from market $j$ to the total forecast error variance. Thus, the magnitude of directional spillover from market $i$ to market $j$ can be defined as:

$$
S_{i j}(H)=\left(\frac{\tilde{\theta}_{i j}(H)}{\sum_{j=1}^{3} \theta_{i j}(H)}\right) \times 100
$$

The net pairwise spillover between market $i$ and $j$ is defined as the difference between the shocks transmitted from market $i$ to market $j$ and those transmitted from $j$ to $i$. The net pairwise spillover index can be estimated as follows:

$$
S_{i j}^{n e t}(H)=\left(\frac{\tilde{\theta}_{i j}(H)}{\sum_{j=1}^{3} \theta_{i j}(H)}-\frac{\tilde{\theta}_{j i}(H)}{\sum_{i=1}^{3} \theta_{j i}(H)}\right) \times 100
$$

Accordingly, $S_{i j}^{\text {net }}(H)>0$ denotes that market $i$ is a net recipient of spillover from market $j$, and $S_{i j}^{\text {net }}(H)<0$ denotes that market $i$ is a net transmitter of spillover to market $j$.

An alternative approach for analyzing the dynamic effects of one market on another market is the impulse response function (IRF). Compared with IRF, one of the main advantages of the method used in this paper is that it allows us to investigate the evolution of volatility spillovers among series during the whole sample periods, particularly in the periods of turmoil, such as the oil price collapse in global financial crisis in 2009 and the bottoming rebound of oil price in the beginning of 2016. Therefore, VAR-MGARCH including dynamic correlation coefficient as well as DY method provide a comprehensive framework for the purpose of this paper, i.e., how China's coal prices interact with prices in the crude oil market and international coal market, especially the dynamic magnitude and directions of the interaction.

\section{Empirical results and further discussion}

\subsection{Evidence for co-movements across different energy markets: DCC estimation results}

In this subsection, we identify the co-movements among the crude oil, Aus_BJ and QHD markets. We estimate the VAR(2)-MGARCH(1,1) model based on Aielli's (2013) cDCC model. The lag length of the VAR process is determined by the Akaike information criterion. For parsimony, the MGARCH $(1,1)$ process has been adopted as suggested by Tsay (2002). Table 3 shows the diagnostic check for model 
specification. In Panel A of Table 3, the statistics of LBS are generally significant, implying volatility clustering in the residuals of VAR process. Therefore, cDCC-MARCH(1,1) is further applied to depict the residuals. Panel B of Table 3 shows that all the Ljung-Box tests for standardized residuals and squared standardized residuals of $\operatorname{VAR}(2)$-cDCC-MARCH $(1,1)$ cannot be rejected at the $5 \%$ significant level in general. Therefore, the diagnostic results in Table 3 suggest that VAR(2)-cDCC$\operatorname{MGARCH}(1,1)$ is adequate for capturing the volatility clustering.

Table 3. Diagnostics for model specification: Ljung-Box test

\begin{tabular}{lcccccc}
\hline \hline & \multicolumn{2}{c}{ Brent } & \multicolumn{4}{c}{ Qus_BJ } \\
\cline { 2 - 6 } & statistic & $p$-value & statistic & $p$-value & statistic & $p$-value \\
\cline { 2 - 6 } & \multicolumn{5}{c}{ Panel A: Ljung-Box tests for residuals of VAR(2) } \\
\hline LB(6) & 1.813 & 0.936 & 1.705 & 0.945 & 10.339 & 0.111 \\
LBS(6) & $144.017^{* * *}$ & 0.000 & 8.057 & 0.234 & $136.698^{* * *}$ & 0.000 \\
\hline \multicolumn{6}{c}{ Panel B: Ljung-Box tests for residuals of VAR(2)-cDCC-MARCH(1,1) } \\
\hline LB(6) & 4.144 & 0.657 & 2.967 & 0.813 & $15.026^{* *}$ & 0.020 \\
LBS(6) & 2.153 & 0.905 & 1.476 & 0.961 & 1.264 & 0.974 \\
\hline \hline
\end{tabular}

Notes: ${ }^{* *}$ and ${ }^{* * *}$ denotes significant at the $5 \%$ and $1 \%$ level, respectively.

Furthermore, Aielli (2013) proposes that if the model is correctly specified, the series $\left(\omega^{\prime} \varepsilon_{t}\right)^{2} /\left(\omega^{\prime} H_{t} \omega\right)$ does not exhibit serial correlation. Here, $\omega$ is weighted vector. In Aielli (2013), equally weighted vector is also used for the test. The Lagrange Multiplier (LM) test of ARCH effect is further adopted to test the null hypothesis of serial uncorrelation, as shown in Table 4 . The results show that the LM tests with one to six lags all do not support the model misspecification.

Table 4. Diagnostics for model specification: LM-ARCH test

\begin{tabular}{lllllll}
\hline \hline & $\operatorname{Lag} 1$ & $\operatorname{Lag} 2$ & $\operatorname{Lag} 3$ & $\operatorname{Lag} 4$ & $\operatorname{Lag} 5$ & $\operatorname{Lag} 6$ \\
\cline { 2 - 6 } LM-test & 0.137 & 0.355 & 0.785 & 1.352 & 2.204 & 2.200 \\
$p$-value & 0.711 & 0.837 & 0.853 & 0.853 & 0.820 & 0.900 \\
\hline \hline
\end{tabular}

Notes: The null hypothesis is no ARCH effects, and alternative hypothesis is ARCH( $p)$ disturbance.

According to the estimation results of the DCC model, the dynamic conditional correlation across different energy markets can be calculated by Equation (8). Figure 3 reports the dynamic changes in the conditional correlations over time. Of particular interest is that the correlations between Aus_BJ and QHD substantially increased since late 2012. It coincides with China's canceling the dual-track pricing for steam $\mathrm{coal}^{8}$, which has made the coal prices in China to be much more market-oriented.

${ }^{8} \mathrm{Li}$ and Sun (2018) summarize the pricing reform of fossil fuel in China in recent years; Yang et al (2016) provide 


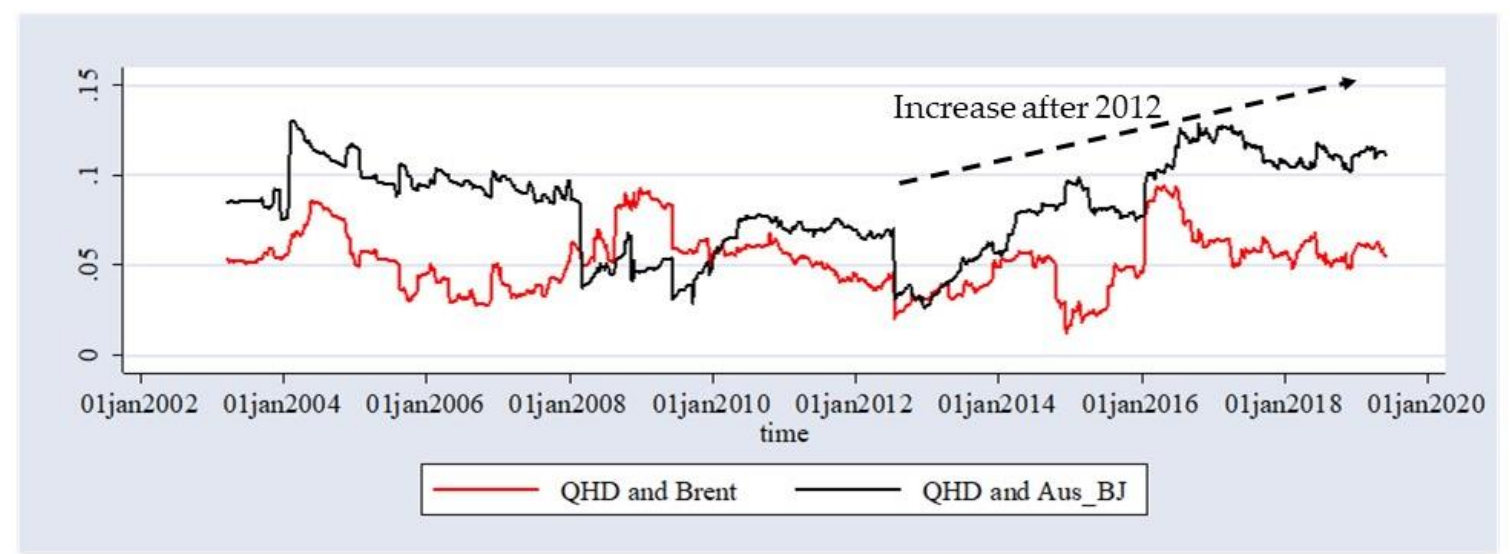

Figure 3. Dynamic conditional correlations

Table 5 presents the descriptive statistics of the conditional correlations. Both the average correlation between QHD and Aus_BJ and that between QHD and Brent oil are small, although they are significant statistically at $1 \%$ level. Several factors might have limited inter-market contagion of these two markets. The first one is China's domestic protectionism for coal mining, by restricting coal imports ${ }^{9}$, given that China's coal supply capacity is much larger than its demand. Second, long-term supply contracts between producers and consumers may also have limited coal buyers' shifting from/to the international coal sellers ${ }^{10}$.

Also, the co-movements between QHD and Brent oil through inter-fuel substitution could be small. Inter-fuel substitution may exist due to i) consumers' shifts between coal and oil; and ii) the changing desirability of holding coal/oil inventories. The first mechanism is time-consuming due to the lock-in to specific equipment (Li and Lin, 2016), indicating small correlation through this channel in weekly frequency. The second mechanism through inventory adjustment may be slight as well due to its minor proportion. According to China's National Bureau of Statistics, coal inventory in China accounted for $11 \%$ in total coal demand in 2016. Internationally, oil inventory in OECD countries took up about 13\% in OECD's oil demand in 2016 (Kilian and Murphy, 2014) ${ }^{11}$.

Table 5. The descriptive statistics and time trends of dynamic correlations

\begin{tabular}{lllll}
\hline \hline Mean & Std.dev & Min & Max & Trend $\left({ }^{*} 10^{-4}\right)$ \\
\hline
\end{tabular}

a detailed policy description on unifying the dual-track pricing mechanism for coal in China.

9 For example, in 2013, there was a debate in China about whether it is reasonable to restrict coal import. The fuse of this debate is that National Energy Board issued a legislation to implement measures for quality control of commercial coal, which limits coal imports mainly from Australia and Indonesia.

10 In 2016, about 50\% of coal is traded through long-term supply contracts. Data is available from: http://www.chinacoal.gov.cn/templet/3/ShowArticle.jsp?id=85305. Accessed at April 21, 2017.

${ }_{11}$ According the website of EIA, oil inventory in the US was 2.03 billion barrel in 2016. Meanwhile, OECD countries consumed 2.09 billion tonnes oil in 2016. Based on the scale factor provided by Kilian and Murphy (2014), the share of oil inventory in total oil demand can be calculated. Data on oil inventory is available from: https://www.eia.gov/dnav/pet/pet stoc wstk dcu nus a.htm. Accessed at June 7, 2017. 


\begin{tabular}{|c|c|c|c|c|c|c|}
\hline & & & & & Sub-period 1 & Sub-period 2 \\
\hline Brent-QHD & $0.053^{* * *}$ & 0.017 & 0.012 & 0.094 & $0.074(0.243)$ & $0.891^{* * *}(0.000)$ \\
\hline Aus_BJ-QHD & $0.083^{* * *}$ & 0.026 & 0.026 & 0.130 & $-1.324^{* * *}(0.000)$ & $1.437^{* * *}(0.000)$ \\
\hline
\end{tabular}

Notes: Sub-periods for Brent-QHD pair is divided by 2012 when the proportion of oil in China's energy mix is increasing comparing to coal. The division for Aus_BJ-QHD is mid-2008 when China switched from coal exporter to coal importer in international coal market. ${ }^{* * *}$ denotes significant at the $1 \%$ level.

Accordingly, if the inter-fuel substitution from crude oil to coal does provide an explanation for the correlation between the global crude oil prices and China's coal prices, it should be expected that conditional correlation should be related to the proportions of coal and oil in China's energy mix. For testing this hypothesis, we regress the time-varying conditional correlation on a time trend:

$$
\rho_{i j, t}=\mu+\tau \times \text { Trend }+\omega_{i j, t}
$$

where Trend is a time trend.

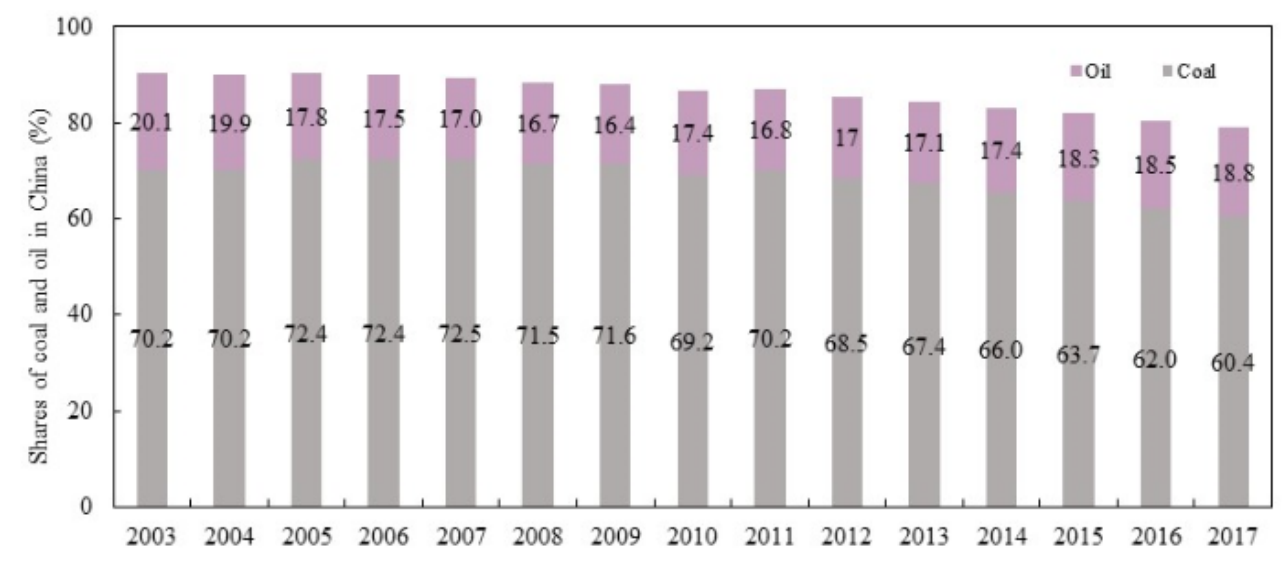

Figure 4. The proportions of coal and oil in China's energy mix (\%)

The results of the regression (16) are shown in the last two columns of Table 5. Since 2012, due to air pollution control policies in China, the share of coal consumption in energy mix has been decreasing while the share of oil keeps increasing (as shown in Figure 4). Therefore, there is a significantly positive time trend for the conditional correlation between QHD and Brent oil in the sub-period after 2012. Before that, the hypothesis of no significant time trend of conditional correlation cannot be rejected. This provides another support for the explanation from inter-fuel substitution.

In contrast, the correlation between QHD and Aus_BJ has decreased before mid-2008, suggesting that China's domestic market and the international coal market have become less interrelated over the sample period. At first glance, it seems unreasonable given the increased links across energy 
markets. In fact, it is consistent with the transition of China's role in the global coal market. Before mid-2008, China was a net coal exporter, however, the volume of coal exports has been decreasing steadily since 2003. After mid-2008, China had transformed into a net coal importer and coal imports had increased for most of the years (as shown in Figure 5). Thus, we regress Equation (16) using the two sub-samples divided as pre and post mid-2008. The coefficients of the time trend are -1.324 before mid-2008 and 1.437 after mid-2008 (both are scaled by 10-4), and the coefficients are both significant at the $1 \%$ significance level. It implies that co-movements in price between the international and China's coal markets could be substantially affected by coal trade scale. In addition, the decline in long-term supply contracts have also contributed to the increasing inter-market contagion ${ }^{12}$.

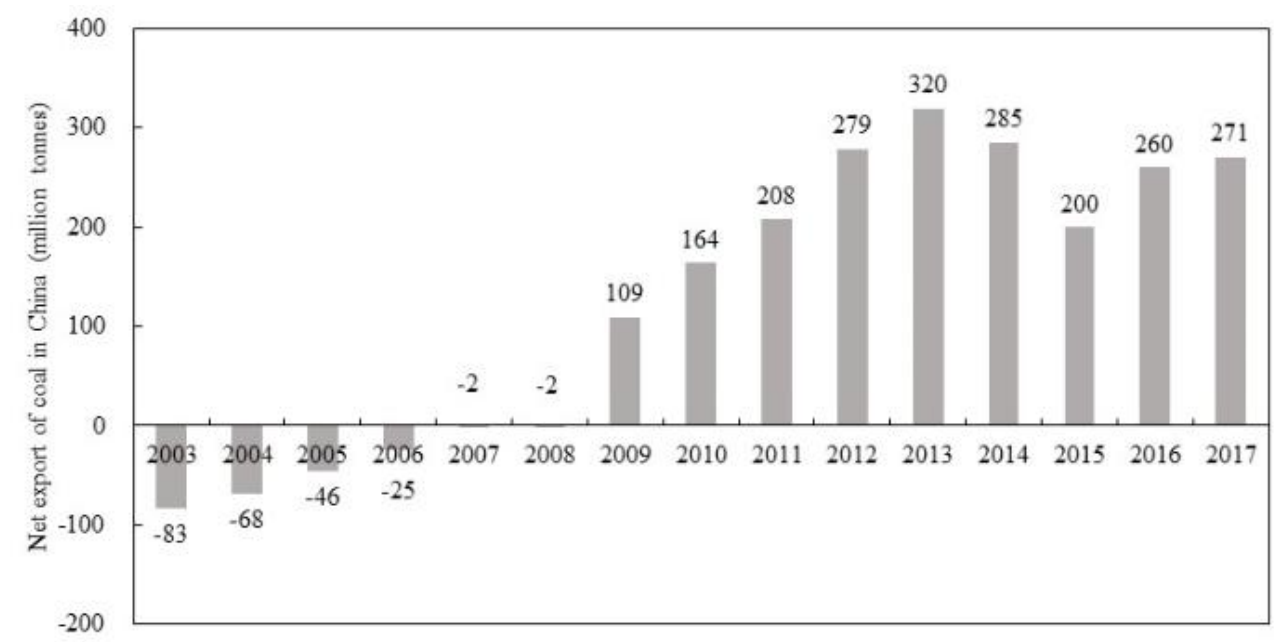

Figure 5. China's coal trade with the international coal market

Notes: The negative values denote net export, and the positive ones denotes net import. The unit is "million tons".

Based on data availability, we use two alternative coal prices (at weekly frequency) in Amsterdam, Rotterdam, and Antwerp (ARA) of Europe and in Appalachia of the US since mid-2008 to conduct the analysis. China almost has no coal trade with these two markets. Events or conditions in China seem unlikely to related to the coal markets in regions that have few or no coal trade with China, because coal markets tend to be regionally segmented. For example, the increased coal import of China from Australia seems unlikely to be able to influence the coal price correlation between China and EU/US. Therefore, if the time trend of conditional correlations truly responds to the scale of coal trade between China and international coal market, we could expect that there should be no or reversed time trend with regard to correlation between China and EU/US. The results in Table A1 of Appendix show that there are no statistically significant coal price correlation between China and EU/US. Also, the correlation with US coal price has no time trend, and with EU coal price has negative trend. Therefore, the results provide further evidence that the scale of coal trade matters for the

12 Ekawan et al. (2006) find that the number of long-term supply contracts is decreasing. 
correlation between coal prices across regional coal markets, which has been captured in the correlation between coal prices in China and Australia.

\subsection{Further evidence for inter-fuel substitution and inter-market contagion from the spillover index}

\subsubsection{Static spillover table}

Although the MGARCH analysis above shows the co-movements across Brent oil, Aus_BJ and QHD coal prices over time; it cannot directly reveal the direction and magnitude of the spillovers of returns and volatilities, which are important for further identifying the originators and time-varying magnitude of inter-fuel substitution and inter-market contagion. For example, the correlations detected by cDCC estimation between Brent oil and QHD do not necessarily mean the spillover from Brent oil market to China's domestic coal market. Instead, it could be China's coal market affecting oil market and thus generating co-movements between Brent oil and QHD.

Hence, the DY approach is further applied to calculate the return and volatility spillovers for given directions. We begin by estimating the overall magnitude of return and volatility spillovers using the whole sample. Subsequently, we would track the time variation of directional spillovers via a rolling sample estimation.

Table 6. Spillover tables for return and volatility

\begin{tabular}{lrrrr}
\hline & & & & return \\
\cline { 2 - 5 } & Brent & Aus_BJ & QHD & Directional from others \\
\hline Brent & 99.19 & 0.22 & 0.59 & 0.81 \\
Aus_BJ & 4.91 & 89.63 & 5.46 & 10.37 \\
QHD & 2.04 & 4.32 & 93.64 & 6.36 \\
Directional to others & 6.95 & 4.54 & 6.05 & 17.54 \\
Directional including own & 106.14 & 94.17 & 99.69 & Spillover Index=5.85\% \\
\hline & & & volatility & \\
\cline { 2 - 5 } & Brent & Aus_BJ & QHD & Directional from others \\
\hline Brent & 89.00 & 0.40 & 10.60 & 11.00 \\
Aus_BJ & 0.50 & 90.96 & 8.54 & 9.04 \\
QHD & 0.71 & 13.87 & 85.42 & 14.58 \\
Directional to others & 1.21 & 14.27 & 19.14 & 34.62 \\
Directional including own & 90.21 & 105.23 & 104.56 & Spillover Index=11.54\% \\
\hline \hline
\end{tabular}

The results of static spillover table are reported in Table 6. By combining all of the cross-market spillover into a single index for full sample, we find that $5.85 \%$ of the forecast error variance comes from spillovers for returns, and $11.54 \%$ for volatilities. Thus, the magnitude of volatility spillover is larger than that of return. The reason for this may lie in that shocks in one energy market would cause the rapid shifts in the market's assessment of uncertainty and thus amplify the volatility in other 
markets (Edwards and Susmel, 2001).

Nonetheless, the static spillover index can only provide prima facie evidence on the average spillover magnitude. Hence, in the next two subsections we provide further evidence using a dynamic rolling-sample analysis in order to explore the dynamics of spillovers for given directions.

\subsubsection{Directional rolling-sample spillovers}

The time-varying estimates of directional spillovers from Brent oil and Aus_BJ to China's coal market are shown in Figure 6. Similar to Zhang and Wang (2014), the model is estimated by using a 50-week rolling windows, and the forecast horizon is 10 weeks. The main results are summarized as follows:

First of all, from 2003 to mid-2019, the directional spillovers to China's coal market fluctuate substantially, which further suggests the necessity of applying a time-varying spillover index rather than a static index. For returns, the maximal magnitude of spillovers is 99.36 from Brent oil and 99.98 for Aus_BJ, indicating that almost all forecast error variance can be explained by either Brent oil or Aus_BJ at certain periods (which could be detected). In contrast, the minimum magnitude of spillovers is nearly zero for both Brent oil and Aus_BJ, which means that China's coal market could be free from the interaction of either Brent oil or Aus_BJ at some points. Similar conclusions can be drawn for volatility spillover, with the exception that the maximal magnitude of spillovers for volatility is 86.03 from Brent oil and 76.37 from Aus_BJ.

(a) Return Spillovers

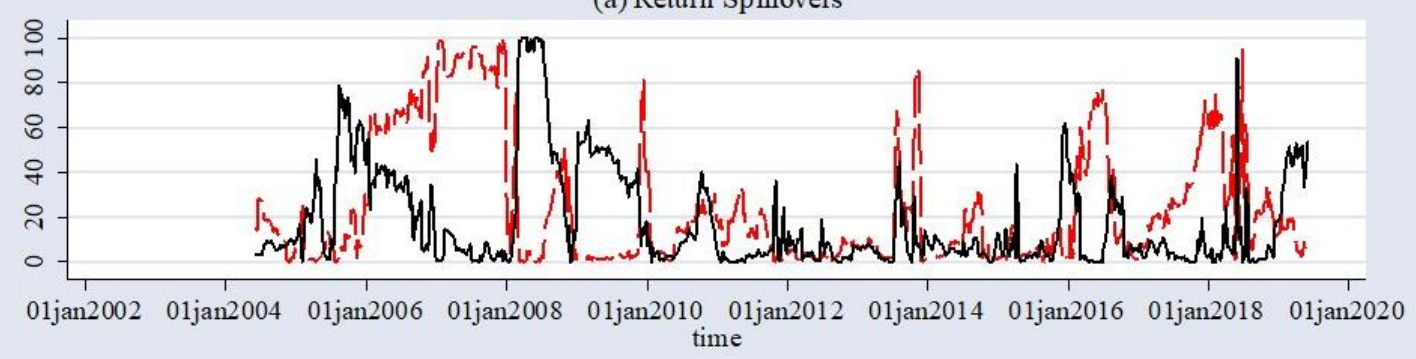

(b) Volatility Spillovers

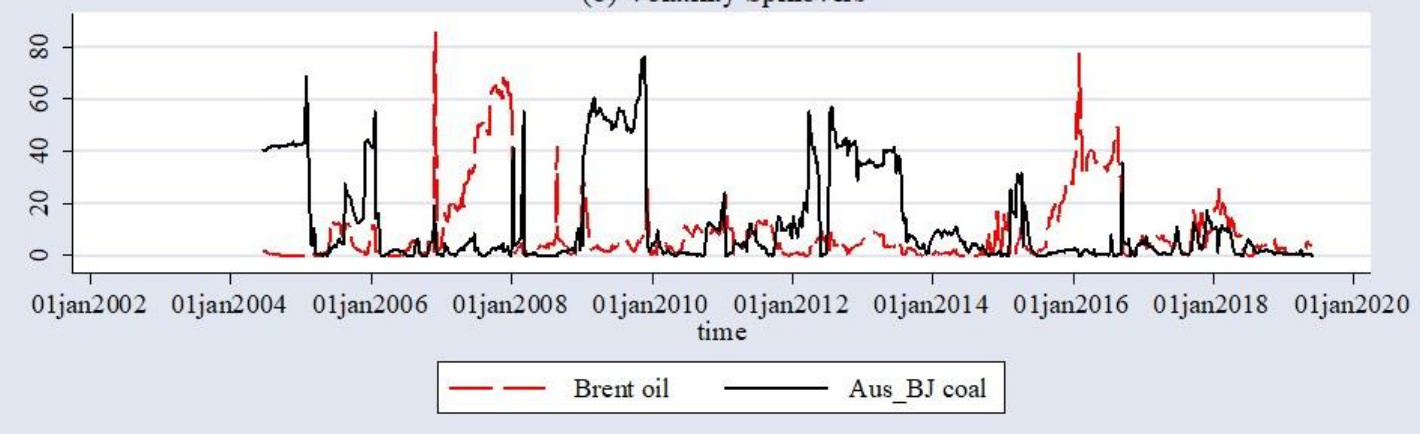

Figure 6. The spillover from Brent oil and Aus BJ to China's coal market

Secondly, the rise in China's coal prices since early 2006 is mainly due to the surge in oil prices; 
while the crash of China's coal prices after the global financial crisis is directly interrelated with Aus_BJ. The largest spike of spillover index, for both returns and volatilities, is in around 2008, implying the strong influence of the global financial crisis on the energy markets. The sustained decreases of energy prices after mid-2014 have also caused turmoil in the energy markets, especially amplified the volatility spillover.

Thirdly, we find evidence of divergent behaviors in the dynamics of return spillovers and volatility spillovers. For example, there is a slow decreasing trend of return spillovers with a few large shocks. With the gradually increasing integration of energy markets, we expect an increasing magnitude of return spillovers. The decreasing trend may have been caused by the bidirectional offset of spillovers from Brent oil to QHD and spillovers from QHD to Brent oil. This is also similar to the spillovers between Aus_BJ and QHD. Contrarily, for volatility spillovers, there are clear shocks with no trend, which is consistent with the volatility clustering as it has been detected by the above MGARCH model.

\subsubsection{Net pairwise directional rolling-sample spillovers}

Accordingly, in order to filter the possible influence of bidirectional offset, we re-calculate the net pairwise spillover index. According to the definition in Equation (15), positive values of this index denote that market $i$ is a net recipient of spillover from market $j$, and negative values denote a net transmission of spillover from market $i$ to market $j$. Hence, these indexes provide a clear representation of the net impact of inter-fuel substitution from Brent oil and inter-market contagion from Aus_BJ to China's coal prices.

For facilitating the comparison, we extend analysis by splitting into two sub-periods, using July 03, 2008 as the break point. There are two main reasons for choosing this break point: i) the crude oil prices peaked at this point and thereafter prices crashed due to the 2008 global financial crisis. ii) China has become a net importer of coal since the mid-2008, while before that, China was a net exporter in the coal market. The 2008 crude oil crisis together with China's role transition at the same time could have strongly influenced the inter-fuel substitution and inter-market contagion across markets. In addition, the break point can also be detected endogenously by testing structural changes on the rolling spillover index ${ }^{13}$. Therefore, the entire sample is divided into two parts for analyzing and comparing purposes, using July 03, 2008 as the break point.

\footnotetext{
13 The procedure proposed by Bai and Perron (2003) is further applied to determine the endogenous structural changes. The test also suggests that mid-2008 is the break point for both return and volatility rolling spillover index.
} 
(a) Return of QHD price

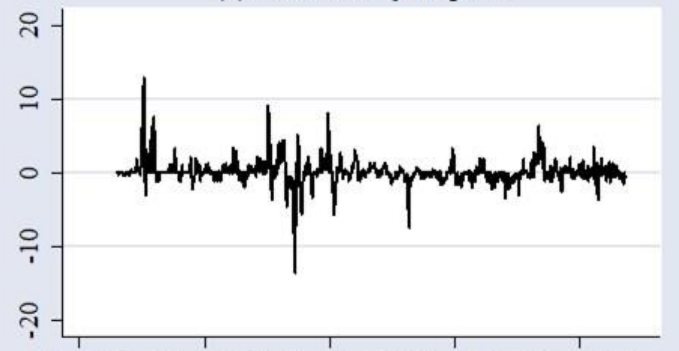

01jan2002 01jan2006 01jan2010 01jan2014 01jan2018

time (b) Return of Brent and Aus_BJ prices

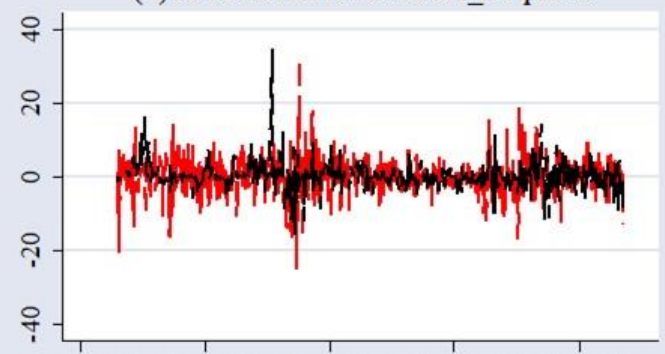

01jan2002 01jan2006 01jan2010 0 jjan2014 01jan2018 -- Aus_BJ coal (c) Return spillover from Brent oil to QHD

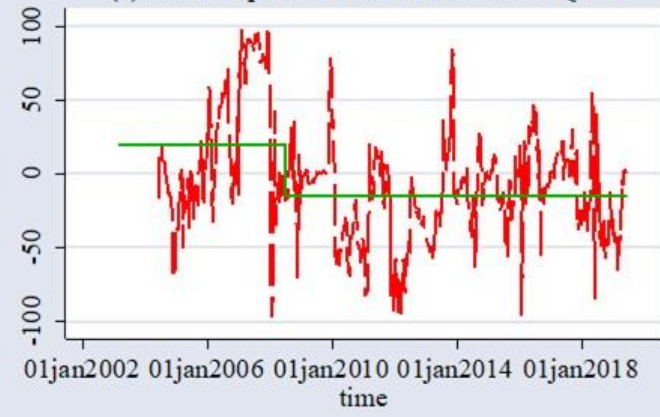

(d) Return spillover from Aus_BJ to QHD

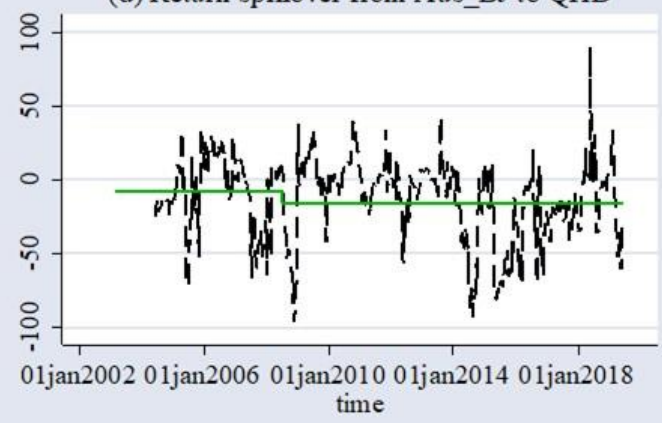

Figure 7. The net pairwise return spillovers for $Q H D$

Notes: the horizontal lines in $(c)$ and $(d)$ are the average magnitudes of return spillovers in two sub-samples.

The results of net pairwise spillover for returns are reported in Figure 7. As shown, before mid2008, the net return spillovers from Brent oil are positive on average, which means that China's coal market was a net recipient of crude oil return shocks. But it has then become a net transmitter of return shocks to crude oil during the sub-period after mid-2008. One reason for this transition could be the relative size of each market in different periods. Coal consumption in China has increased rapidly and substantially since 2003, and by 2017 China's coal consumption has doubled (BP, 2018). China now accounts for more than $50 \%$ of world's coal consumption. In comparison, the global demand increase for crude oil is less than $20 \%$ during the same period (BP, 2018). Thus, the relative size of China's coal market to the global crude oil market has been promoted substantially. This finding suggests that crude oil prices have become more endogenous in recent years. It is somewhat consistent with the findings by Kilian (2009) and Lin and Li (2015c) which suggest that the crude oil price is endogenous to global energy market.

Meanwhile, China's coal market is always a net return shocks transmitter to the international coal market both before and after the mid-2008 periods. China plays an important role in the international coal market as China is consuming more than half of coal globally. The impact from China's coal market to international market would be larger than the reverse. For example, in 2013, China's coal import from Australia was 88.2 million tons, accounting for $24.6 \%$ of Australian coal 
exports. Yet, it only accounted for $2.1 \%$ of China's coal consumption in that year. Further, with increasing coal import, the magnitude of inter-market contagion from China to international has improved: the average net spillover before mid-2008 is -7.53 , while the value after mid-2008 is -15.62 .

(a) Volatility of QHD price

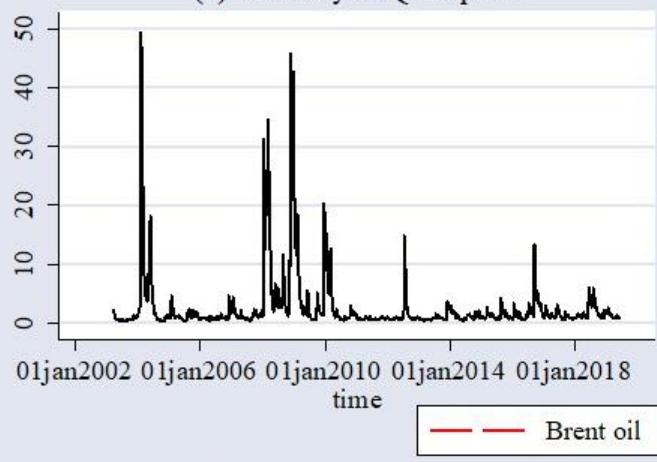

(c) Volatility spillover from Brent to QHD

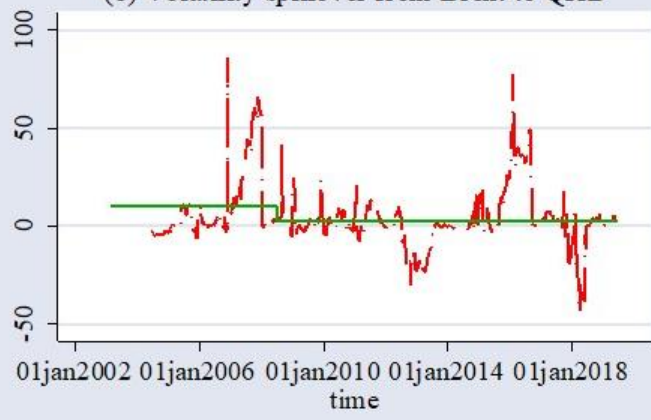

(b) Volatility of Brent and Aus_BJ prices

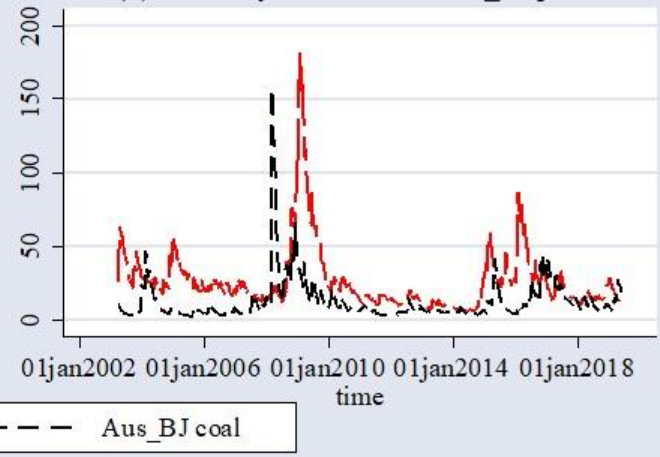

(d) Volatility spillover from Aus_BJ to QHD

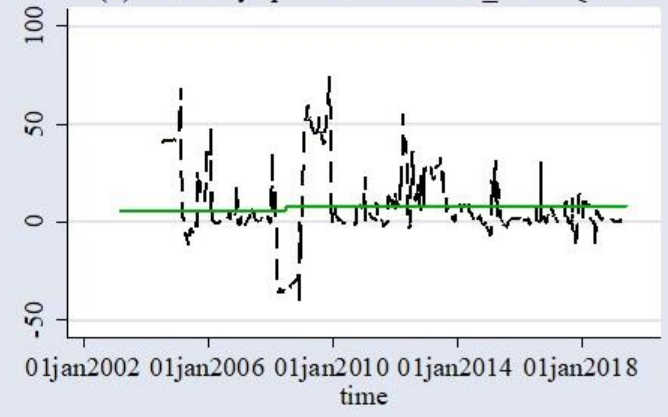

Figure 8. The net pairwise volatility spillovers for QHD

Notes: the horizontal lines in (c) and (d) are the average magnitudes of volatility spillovers in two subsamples.

Figure 8 shows the net pairwise spillover for volatility. Compared with the net return spillover in Figure 7, the net volatility spillover is small generally but with several large shocks, especially the turmoil in around 2008 and the energy price crash after 2014. An interesting finding is that China is a net recipient of volatility shocks from both crude oil market and international coal market in the two subperiods, as detected by the positive net spillover index on average. This could be caused by China's less developed energy financial market, which may have prevented the large price fluctuations by speculation using financial tools. We infer that crude oil market and international coal market could be more exposed to political/economic events as well as financial speculation, amplifying the volatility in these markets. The amplified volatility would transmitted to China's domestic coal market.

Table 7 summarizes the averaged magnitude of net pairwise spillover before and after mid-2008, for both return and volatility. As shown, China's coal prices have tight relationship with Brent oil in 
magnitude, but the connection with international coal market has been increasing. For the subperiod after mid-2008, the net pairwise spillovers of both return and volatility in magnitude from Aus_BJ surpassed those from Brent oil. Potential reasons include the rise of coal trade, decreasing long-term supply contracts (Ekawan et al., 2006), as well as China's coal pricing reform. It could be concluded from Table 7 that inter-fuel substitution between coal and crude oil used to dominates the energy price interactions, but the pattern may have been changed because of the increased impact from intermarket contagion between China's and international coal markets.

Table 7. The magnitude of net pairwise spillover before and after mid-2008

\begin{tabular}{lcccc}
\hline \hline & \multicolumn{2}{c}{ Return } & \multicolumn{2}{c}{ Volatility } \\
\cline { 2 - 5 } & Brent oil & Aus_BJ & Brent oil & Aus_BJ \\
\hline before mid-2008 & 20.006 & -7.527 & 10.022 & 5.961 \\
after mid-2008 & -15.469 & -15.623 & 2.253 & 8.015 \\
\hline \hline
\end{tabular}

For robustness check, we use 100-week rolling windows to estimate the net pairwise directional spillovers, as reported in Figure 9. In general, the earlier findings appear largely robust: i) Before mid2008, China's coal price return is largely affected by crude oil price returns, but crude oil price has become more endogenous as a net recipient of return shocks from China's coal price. ii) China plays a more and more important role in affecting the international coal returns. iii) China is a net recipient of volatility shocks before and after mid-2008. iv) Inter-fuel substitution was a more important force in the interactions across energy markets, but the situation is switching to inter-market contagion with China's interaction with international coal market increasing ${ }^{14}$.

${ }^{14}$ From the pre- to pos-subperiods, the magnitude of both return spillover and volitivity spillover from/to crude oil market decreases, but increases from/to international coal market. 
(a) Return spillover from Brent to QHD

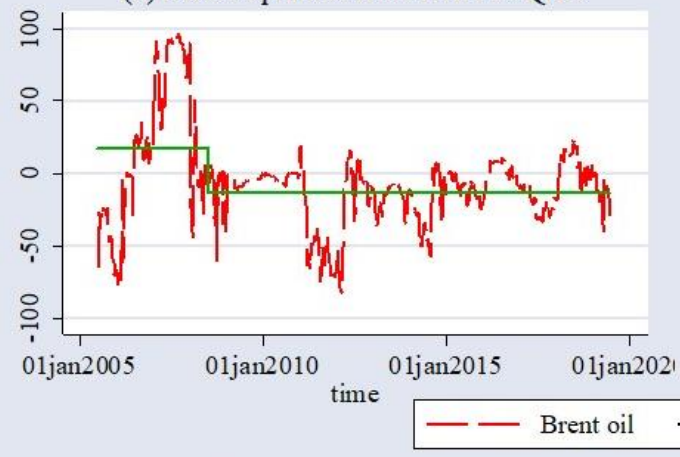

(c) Volatility spillover from Brent to QHD

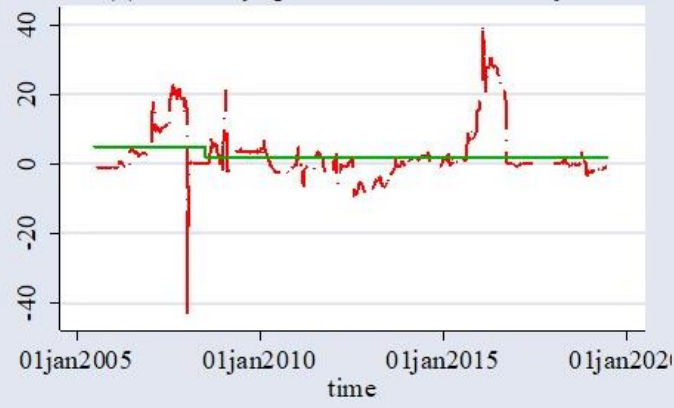

(b) Return spillover from Aus_BJ to QHD

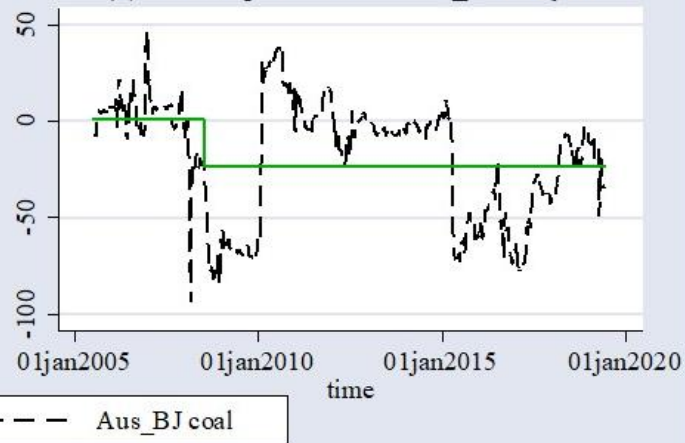

(d) Volatility spillover from Aus_BJ to QHD

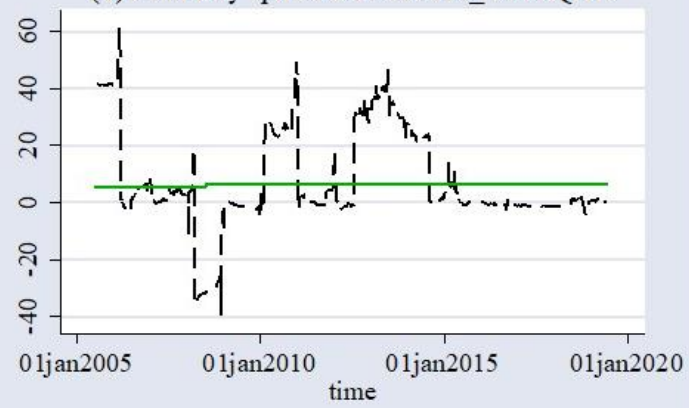

Figure 9. Sensitivity analysis using 100-week rolling windows

Notes: The horizontal lines are the average magnitudes of volatility spillovers in two sub-samples.

\section{Summary and concluding remarks}

Coal has largely fueled the rapid economic growth, urbanization and industrialization in China and that has led to China accounting for more than half of global coal demand. The share of coal now is still about 60 percent in China's energy mix after the striving in recent years to regulate coal consumption. Therefore, the price of coal is particularly essential for China's economy by inevitably affecting the production costs and altering investment incentives.

Inter-fuel substitution of crude oil and inter-market contagion of international coal market may lead to China's coal prices interacting with crude oil prices and international coal prices. Based on time series dataset covering energy prices in global and China's markets from 2003 to 2019, in this study we provide further understanding on the dynamic changes in China's coal prices and its determinants by testing how the China's coal prices are related to international coal prices and crude oil prices in the global market. The ongoing integration of energy markets and the substituting potential across energy types are likely to affect the energy price co-movements through inter-market contagion and/or inter-fuel substitution.

We found that the co-movement between China's coal price and Brent oil price largely hinges on the shares of oil and coal in China's energy mix. Meanwhile, the co-movement between China's coal 
price and the international coal price also has different trends before and after mid-2008, depending on the amount of international coal trade in China (i.e., importing and/or exporting). The results further demonstrate that inter-fuel substitution plays an important role in the interaction of China's coal market with other energy markets, yet the inter-market contagion has generated increasing impacts.

As for the direction of these co-movements, China has become an originator for driving the returns of crude oil and the international coal market, implying that crude oil price may be partly endogenous to China's coal price after mid-2008. The endogeneity of the crude oil price suggests that China's coal price changes would be a factor driving crude oil prices. However, China's coal market is found to be still a net volatility recipient through inter-fuel substitution from crude oil market and inter-market contagion from international coal market. With the newly development of China's future market for coal, the interesting question that arises is how to avoid large volatilities caused by the crude oil prices and international coal prices.

\section{Appendix}

Table A1. The descriptive statistics and time trends of correlations with alternative coal prices

\begin{tabular}{lccccc}
\hline \hline & Mean & Std.dev & Min & Max & Trend $\left({ }^{*} 10^{-4}\right)$ \\
\hline EU-QHD & 0.093 & 0.063 & -0.228 & 0.296 & $-0.630^{* * *}(0.005)$ \\
US-QHD & 0.034 & 0.047 & -0.155 & 0.451 & $-0.230(0.187)$ \\
\hline \hline
\end{tabular}

Notes: ${ }^{* * *}$ denotes significant at the $1 \%$ level.

\section{Acknowledgements}

The paper is supported by National Natural Science Foundation of China (No: 71703120), Humanities and Social Science Fund of the Ministry of Education (No: 17YJC790068), China Postdoctoral Science Foundation (No. 2016M602784) and Special Foundation of China Postdoctoral Science (No. 2017T100729).

\section{Reference}

[1]. Agbeyegbe T D. An inverted U-shaped crude oil price return-implied volatility relationship[J]. Review of Financial Economics, 2015, 27: 28-45.

[2]. Ahmad W. An analysis of directional spillover between crude oil prices and stock prices of clean energy and technology companies[J]. Research in International Business and Finance, 2017, 42: 376389.

[3]. Aielli G P. Dynamic conditional correlation: On properties and estimation[J]. Journal of 
Business \& Economic Statistics, 2013, 31(3): 282-299.

[4]. Antonakakis N, Cunado J, Filis G, et al. Oil volatility, oil and gas firms and portfolio diversification[J]. Energy Economics, 2018, 70: 499-515.

[5]. Apostolakis G, Papadopoulos A P. Financial stress spillovers in advanced economies[J]. Journal of International Financial Markets, Institutions and Money, 2014, 32: 128-149.

[6]. Arouri M E H, Jouini J, Nguyen D K. On the impacts of oil price fluctuations on European equity markets: Volatility spillover and hedging effectiveness[J]. Energy Economics, 2012, 34(2): 611617.

[7]. Asche F, Oglend A, Osmundsen P. Gas versus oil prices the impact of shale gas[J]. Energy Policy, 2012, 47: 117-124.

[8]. Atkeson A, Kehoe P J. Models of energy use: Putty-putty versus putty-clay[J]. American Economic Review, 1999, 89(4): 1028-1043.

[9]. Bachmeier L J, Griffin J M. Testing for market integration crude oil, coal, and natural gas[J]. The Energy Journal, 2006: 55-71.

[10]. Bai J, Perron P. Computation and analysis of multiple structural change models[J]. Journal of Applied Econometrics, 2003, 18(1): 1-22.

[11]. Barro R. Macroeconomics: A modern approach[M]. Cengage Learning, 2007.

[12]. Batten J A, Brzeszczynski J, Ciner C, et al. Price and volatility spillovers across the international steam coal market[J]. Energy Economics, 2019, 77: 119-138.

[13]. British Petroleum, BP statistical review of world energy 2018 workbook, 2018.

[14]. Chen Z M. Inflationary effect of coal price change on the Chinese economy[J]. Applied Energy, 2014, 114: 301-309.

[15]. Diebold F X, Yilmaz K. Measuring financial asset return and volatility spillovers, with application to global equity markets[J]. The Economic Journal, 2009, 119(534): 158-171.

[16]. Diebold F X, Yilmaz K. Better to give than to receive: Predictive directional measurement of volatility spillovers[J]. International Journal of Forecasting, 2012, 28(1): 57-66.

[17]. Edwards S, Susmel R. Volatility dependence and contagion in emerging equity markets[J]. Journal of Development Economics, 2001, 66(2): 505-532.

[18]. Ekawan R, Duchêne M, Goetz D. The evolution of hard coal trade in the Pacific market[J]. Energy Policy, 2006, 34(14): 1853-1866.

[19]. Engle R. Dynamic conditional correlation: A simple class of multivariate generalized autoregressive conditional heteroskedasticity models[J]. Journal of Business \& Economic Statistics, 2002, 20(3): 339-350.

[20]. Engle R F, Ito T, Lin W L. Meteor showers or heat waves? heteroskedastic intra-daily volatility in the foreign exchange market[J]. Econometrica, 1990, 58: 525-542. 
[21]. Erdős P. Have oil and gas prices got separated?[J]. Energy Policy, 2012, 49: 707-718.

[22]. Ewing B T, Malik F. Volatility transmission between gold and oil futures under structural breaks[J]. International Review of Economics \& Finance, 2013, 25: 113-121.

[23]. Ewing B T, Malik F, Ozfidan O. Volatility transmission in the oil and natural gas markets[J]. Energy Economics, 2002, 24(6): 525-538.

[24]. Gardebroek C, Hernandez M A. Do energy prices stimulate food price volatility? Examining volatility transmission between US oil, ethanol and corn markets[J]. Energy Economics, 2013, 40: 119-129.

[25]. Guo J, Zheng X, Chen Z M. How does coal price drive up inflation? Reexamining the relationship between coal price and general price level in China[J]. Energy Economics, 2016, 57: 265276.

[26]. Kilian L. Not all oil price shocks are alike: Disentangling demand and supply shocks in the crude oil market[J]. The American Economic Review, 2009, 99(3): 1053-1069.

[27]. Kilian L, Murphy D P. The role of inventories and speculative trading in the global market for crude oil[J]. Journal of Applied Econometrics, 2014, 29(3): 454-478.

[28]. $\mathrm{Li} \mathrm{J}$, Lin B. Inter-factor/inter-fuel substitution, carbon intensity, and energy-related $\mathrm{CO}_{2}$ reduction: Empirical evidence from China[J]. Energy Economics, 2016, 56: 483-494.

[29]. Li J, Lin B. Does energy and $\mathrm{CO}_{2}$ emissions performance of China benefit from regional integration?[J]. Energy Policy, 2017, 101: 366-378.

[30]. Li J, Sun C. Towards a low carbon economy by removing fossil fuel subsidies?[J]. China Economic Review, 2018, 50: 17-33.

[31]. Lin B. Designing the mechanism of coal-electricity price linkage[M]. Science Press, Beijing, 2014. (in Chinese)

[32]. Lin B, Li J. Analyzing cost of grid-connection of renewable energy development in China[J]. Renewable and Sustainable Energy Reviews, 2015a, 50: 1373-1382.

[33]. Lin B, Li J. The spillover effects across natural gas and oil markets: Based on the VECMGARCH framework[J]. Applied Energy, 2015b, 155: 229-241.

[34]. Lin B, Li J. The determinants of endogenous oil price: Considering the influence from China[J]. Emerging Markets Finance and Trade, 2015c, 51(5): 1034-1050.

[35]. Lin B, Wesseh P K, Appiah M O. Oil price fluctuation, volatility spillover and the Ghanaian equity market: Implication for portfolio management and hedging effectiveness[J]. Energy Economics, 2014, 42: 172-182.

[36]. Lin B, Jiang Z. Estimates of energy subsidies in China and impact of energy subsidy reform[J]. Energy Economics, 2011, 33(2): 273-283.

[37]. Lin Y, Cai F and $\mathrm{Li} \mathrm{Z}$. Complete information and the reform of state owned 
enterprises[M]. Truth \& Wisdom Press in Shanghai, 2014. (in Chinese)

[38]. Malik F, Ewing B T. Volatility transmission between oil prices and equity sector returns[J]. International Review of Financial Analysis, 2009, 3(18): 95-100.

[39]. Malik F, Hammoudeh S. Shock and volatility transmission in the oil, US and Gulf equity markets[J]. International Review of Economics \& Finance, 2007, 16(3): 357-368.

[40]. Parsley D C, Wei S J. Explaining the border effect: The role of exchange rate variability, shipping costs, and geography[J]. Journal of International Economics, 2001, 55(1): 87-105.

[41]. Sadorsky P. Correlations and volatility spillovers between oil prices and the stock prices of clean energy and technology companies[J]. Energy Economics, 2012, 34(1): 248-255.

[42]. Silvennoinen A, Teräsvirta T. Multivariate GARCH models[M]. Handbook of financial time series. Springer Berlin Heidelberg, 2009: 201-229.

[43]. Serletis A, Xu L. Volatility and a century of energy markets dynamics[J]. Energy Economics, 2016, 55: 1-9.

[44]. Tsay, R.S. Analysis of financial time series, 2nd edition, 2002, Wiley.

[45]. Wu H X, Li S P. Volatility spillovers in China's crude oil, corn and fuel ethanol markets[J]. Energy Policy, 2013, 62: 878-886.

[46]. Yang, Y., Zeng, M., Xue, S., Wang, J., \& Li, Y. (2018). Unifying the "dual-track" pricing mechanism for coal in China: Policy description, influences, and suggestions for government and generation enterprises. Resources, Conservation and Recycling, 129, 402-415.

[47]. Zhang B, Wang P. Return and volatility spillovers between china and world oil markets[J]. Economic Modelling, 2014, 42: 413-420.

[48]. Zivot E, Andrews D W K. Further evidence on the great crash, the oil-price shock, and the unit-root hypothesis[J]. Journal of Business \& Economic Statistics, 2002, 20(1): 25-44. 